\title{
MRI detects coronary vessel wall thickening with age in healthy subjects
}

\author{
Andrew D Scott ${ }^{\text {* }}$, Jennifer Keegan ${ }^{2}$, Raad H Mohiaddin², David N Firmin ${ }^{1}$ \\ From 2011 SCMR/Euro CMR Joint Scientific Sessions \\ Nice, France. 3-6 February 2011
}

\section{Objective}

To investigate the effects of ageing on the coronary vessel wall of healthy subjects using MR.

\section{Background}

Autopsy studies $[1,2]$ and $\mathrm{x}$-ray $\mathrm{CT}$ in older subjects with suspected disease [3] have demonstrated increasing coronary vessel thickness with age. There is, however, a need for a radiation-free non-invasive technique for use in longitudinal studies of coronary vessel wall morphology. Recently 3D MR coronary vessel wall imaging with retrospective beat-to-beat respiratorymotion-correction (B2B-RMC) [4], which uses 3D low resolution data acquired immediately before the main imaging data to retrospectively correct respiratory motion, has demonstrated great promise [5]. We propose that 3D high resolution MR with B2B-RMC can demonstrate coronary vessel wall thickening with age in healthy subjects.

\section{Methods}

21 healthy subjects with no history of cardiovascular disease (mean age $39 \pm 13$, range $22-62,11$ female) were recruited. Studies were performed on a $1.5 \mathrm{~T}$ Siemens Avanto scanner. Cross-sectional vessel wall imaging was performed in the proximal right coronary artery ( $<40 \mathrm{~mm}$ from origin) using a 3D spiral acquisition with B2B-RMC $(0.7 \times 0.7 \times 3 \mathrm{~mm}$ resolution, 8 slices reconstructed to $16 \times 1.5 \mathrm{~mm}$, duration 600 cardiac cycles assuming $100 \%$ respiratory efficiency) and alternate Rwave cardiac gating. Data were acquired in the coronary rest period, as determined from a cine acquisition in the imaging plane. Circular regions of interest were drawn around the inner and outer coronary vessel wall on one

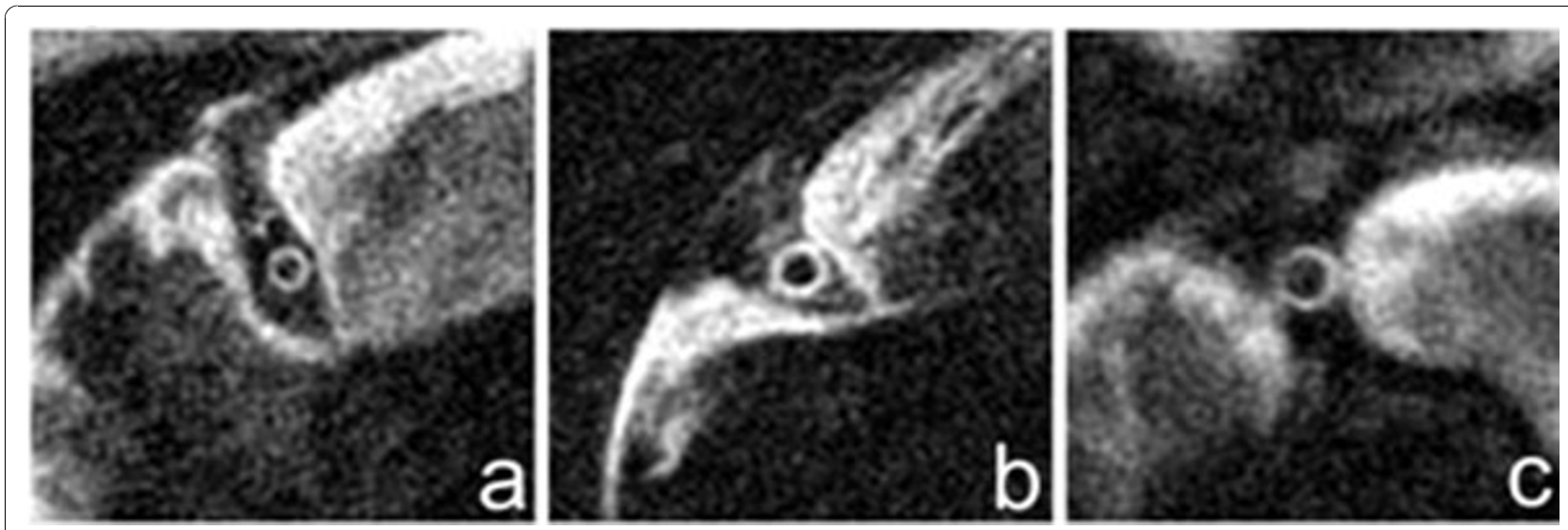

Figure 1 Example images obtained from three male healthy subjects aged 24 (wall thickness 1.02mm, W/OW 0.69) (a), aged 40 (wall thickness $1.38 \mathrm{~mm}$, W/OW 0.73) (b) and aged 59 (wall thickness $1.53 \mathrm{~mm}$, W/OW 0.70) (c).

${ }^{1}$ Imperial College London, London, UK

Full list of author information is available at the end of the article

(c) 2011 Scott et al; licensee BioMed Central Ltd. This is an open access article distributed under the terms of the Creative Commons 

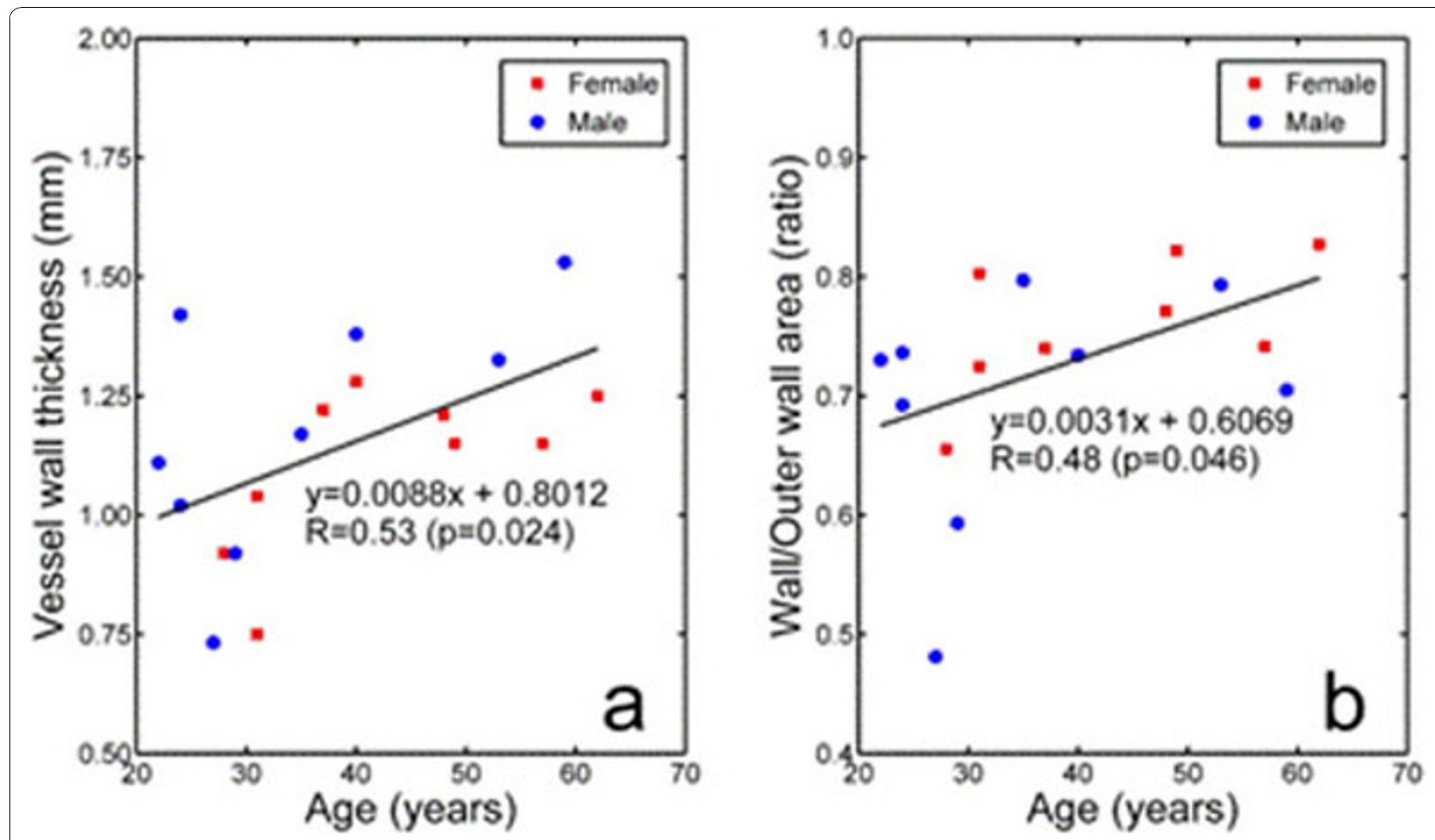

Figure 2 The effects of ageing on the coronary vessel wall as assessed by high resolution MR imaging. Vessel wall thickness (a) and W/OW (b) demonsrate a significant positive correlation with age.

central slice from each 3D acquisition. Average vessel wall thickness and wall/outer wall (lumen + vessel wall) area $(\mathrm{W} / \mathrm{OW})[6]$ were calculated.

\section{Results}

Example images are shown in figure 1. In three subjects $(14 \%)$ the images were rejected due to poor image quality caused by cardiac or respiratory motion. In the remaining 18 subjects, mean vessel wall thickness was $1.14 \pm 0.22 \mathrm{~mm}$ and mean W/OW was $0.727 \pm 0.085$. Vessel wall thickness and W/OW increase by $0.088 \mathrm{~mm}$ $(\mathrm{R}=0.53, \mathrm{p}=0.024$,figure $2 . \mathrm{a})$ and $0.031(\mathrm{R}=0.48, \mathrm{p}=0.048$, figure $2 . \mathrm{b})$ per decade respectively.

\section{Discussion}

For the first time using MR, we have demonstrated significantly increasing vessel wall thickness with age in a small cohort of healthy subjects at $0.088 \mathrm{~mm}$ per decade. The proportion of vessel that is vessel wall (W/OW) also increases with age at 0.031 per decade $(\mathrm{R}=0.48)$. The strength of this correlation is similar to that obtained in larger studies of carotid wall thickening in healthy subjects $(R=0.50$ males and $R=0.46$ females [7]).

\section{Author details}

${ }^{1}$ Imperial College London, London, UK. ${ }^{2}$ The Royal Brompton and Harefield NHS Foundation Trust, London, UK.

Published: 2 February 2011

\section{References}

1. Velican: Atherosclerosis 1980.

2. Ozolanta: Med Eng Phys 1998.

3. Matsunaga: Circulation J 2009.

4. Keegan: JMRI 2007.

5. Scott: JMRI.

6. Saam: JCMR 2005.

7. Keenan: Atherosclerosis 2009.

doi:10.1186/1532-429X-13-S1-047

Cite this article as: Scott et al:: MRI detects coronary vessel wall thickening with age in healthy subjects. Journal of Cardiovascular Magnetic Resonance 2011 13(Suppl 1):O47. 